\title{
From Bench to Bedside
}

\section{From Bench to Bedside: It's Cold in There-Isn't It Time We Gave Our Implants a Coat?}

\author{
Benjamin K. Potter MD
}

II mplant-related infections have existed, and proven problematic, for as long as orthopaedic surgeons have been placing hardware.

A Note from the Editor-In-Chief:

I am pleased to present the next installment of "From Bench to Bedside," a quarterly column by Benjamin K. Potter MD. Dr. Potter is a clinician-scientist in the Department of Orthopaedics at Walter Reed National Military Medical Center and in the Department of Surgery at the Uniformed Services University of Health Sciences, as well as the Deputy Editor for Translational Orthopaedic Research at $\mathrm{CORR}^{\circledR}$. His column will investigate important developments that are making-or are about to make-the transition from the laboratory to clinical practice, as well as technologies and approaches that have recently made that jump.

The author certifies that he, or any member of his immediate family, has no funding or commercial associations (eg, consultancies, stock ownership, equity interest, patent/ licensing arrangements, etc) that might pose a conflict of interest in connection with the submitted article.

All ICMJE Conflict of Interest Forms for authors and Clinical Orthopaedics and Related Research ${ }^{\mathbb{B}}$ editors and board members are on file with the publication and can be viewed on request.

The opinions expressed are those of the writers, and do not reflect the opinion or policy of $C O R R^{\mathbb{R}}$ or the Association of Bone and Joint Surgeons ${ }^{\circledR}$.

The author is an employee of the US

Government and this work was prepared as
Many factors make these infections hard to treat and harder still to eradicate. Surgeons and patients prefer to retain implants when possible, and sometimes-such as in patients with

part of his official duties. As such, there is no copyright to transfer. The views expressed in this article are those of the author and do not necessarily reflect the official policy or position of the Department of the Army, Department of the Navy, Department of Defense, nor the U.S. Government. I certify that all individuals who qualify as authors have been listed; each has participated in the conception and design of this work, the analysis of data, the writing of the document, and the approval of the submission of this version; that the document represents valid work; that if I used information derived from another source, I obtained all necessary approvals to use it and made appropriate acknowledgements in the document; and that each takes public responsibility for it. Nothing in the presentation implies any Federal/DOA/ DON/DOD endorsement. The author received no financial support for this editorial.

\section{B. K. Potter MD ( $\square)$}

Department of Orthopaedics, Walter Reed National Military Medical Center, 8901 Wisconsin Ave, America Building (19), 2nd Floor - Ortho, Bethesda, MD 20889, USA

e-mail: Benjamin.k.potter.mil@mail.mil

B. K. Potter MD

Department of Surgery, Uniformed Services University of Health Sciences, Bethesda, MD, USA healing fractures or unstable vertebral columns-one needs to do so. Some bacteria form biofilms, which reduce the efficacy of antibiotic treatments. Other factors relating to the patient (such as immunosuppression, malnutrition, and diabetes) and the infecting organism (like antibiotic resistance) further complicate matters. Infection after limb-threatening, open lower-extremity fractures occur in as many as $25 \%$ of patients [10], but less infection-prone procedures, such as the fixation of closed fractures and primary total joint arthroplasty (TJA), represent the bulk of the national disease burden in this regard because those procedures are so much more common and because they can be more expensive to manage. Costs associated with the treatment of a patient with an infected TJA can exceed USD 90,000 [6]. There are also human costs in terms of morbidity-which can be staggering-and mortality, which, though rare, are always tragic.

The idea of preventing or mitigating implant-related infections via bioactive (generally antimicrobial) coatings or bonded materials is not at all new [11]. However, numerous techniques hold promise in this regard, as both in vitro culture and in vivo animal studies have demonstrated $[4,5]$. 
These include antibiotic, silver, iodine, and antiseptic coatings to name only a few. Actual coating and/or bonding techniques also vary, including covalent bonding, sol-gels, and plasmasprays, with or without biocompatible or biodegradable carriers with variable antimicrobial-sulfate, hydroxyapatite, and chitosan [1-5, 7, 9, 12].

Although some promising work has been done in animal models, with the most prevalent, and perhaps most promising, approaches typically including vancomycin or silver $[1,2,7$, $9,12]$, no relevant device or technique is, to my knowledge, currently being evaluated in humans for FDA approval. So it seems our devices must remain out in the biologic "cold" without a coat (or coating) for at least some time to come. Once approval is achieved by some implants, it is likely that the market will rapidly develop a veritable glut of available siblings in short order, due to the so-called 501(k) mechanism for "substantially equivalent" (but hopefully not patentinfringing) device approval.

When that happens, our work as practicing surgeons - and skeptical readers - will begin in earnest. There is little doubt that most of these coated implants will have been demonstrated effective for their primary purpose of preventing or mitigating established infections in animals and tightly constrained clinical protocols. Will they be effective in more-general practice settings? Will they generate unintended consequences or new kinds of harm? We will need to read, and follow, the evolving research closely to find out before putting them into common practice. Despite the almost comical expense of many orthopaedic implants, the second-order bar of costeffectiveness, either in reality or via mathematical sleight-of-hand, may also be achieved due to the overwhelming medical costs (not to mention human costs, lost income, etc...) associated with orthopaedic infections.

Once these two bars, or at least that of demonstrable effectiveness, are met, we must endeavor to continue to scrutinize our own clinical results, along with manufacturers' claims, in other areas. Efficacy, even with the absence of overt complications from relatively small, efficacy-demonstrating studies, absolutely does not equate to safety, as recently highlighted in another $C O R R^{\circledR}$ editorial [8]. Likewise, will bio-effective concentrations of these coatings adversely affect fracture healing for fixation devices, limiting utility, or press-fit ingrowth of TJA implants, decreasing device longevity even as infection rates fall? What about coating(s) effect on the biologic ballet of TJA tribology and wear? And these issues say nothing of concerns regarding antimicrobial resistance, allergic, foreign body or other host reactions, and so forth.

I, for one, will welcome the addition of effective implant coatings into our orthopaedic armamentarium. I believe that such techniques have greater potential to change the landscape of orthopaedic than any other technology currently on the horizon-there may be no better way to insulate our vulnerable devices against the "biologic cold." When these devices do eventually arrive, however, we must individually and collectively endeavor to incorporate them into our practices with the appropriate scrutiny and due diligence that we owe both our patients and ourselves.

\section{References}

1. Antoci V Jr, Adams CS, Hicock NJ, Shapiro IM, Parvizi J. Vancomycin bound to Ti rods reduces periprosthetic infection. Clin Orthop Relat Res. 2007;461:88-95.

2. Cheng H, Li Y, Huo K, Gao B, Xiong W. Long-lasting in vivo and in vitro antibacterial ability of nanostructured titania coating incorporated with silver nanoparticles. $J$ Biomed Materials Res. 2014;102: 3488-3499.

3. Darouiche RO, Mansouri MD, Zakarevicz D, Alsharif A, Landon GC. In vivo efficacy of antimicrobial-coated devices. J Bone Joint Surg Am. 2007;89:792-797. 


\section{From Bench to Bedside}

4. Goodman SB, Yao Z, Keeney M, Yang F. The future of biologic coatings for orthopaedic implants. Biomaterials. 2013;34:3174-3183.

5. Ketonis C, Parvizi J, Jones LC. Evolving strategies to prevent implant-associated infections. $J \mathrm{Am}$ Acad Orthop Surg. 2012;20:478-480.

6. Kurtz SM, Lau E, Watson H, Schmier JK, Parvizi J. Economic burden of periprosthetic joint infection in the United States. J Arthroplasty. 2012;27(8 Suppl 1):61-65.

7. Jennings JA, Carpenter DP, Troxel KS, Beenken KE, Smeltzer MS, Courtney HS, Haggard WO. Novel antibiotic-loaded point-of- care implant coating inhibits biofilm. [Published online ahead of print January 21, 2015. Clin Orthop Relat Res. DOI 10.1007/s119999-0144130-4138.

8. Leopold SS. Editorial: When "safe and effective" becomes dangerous. Clin Orthop Relat Res.2014;472: 1999-2001.

9. Liu Y, Zheng Z, Zara JN, Hsu C, Soofer DE, Lee KS, Siu RK, Miller LS, Zhang X, Carpenter D, Wang C, Ting K, Soo C. The antimicrobial and osteoinductive properties of silver nanoparticle/poly (DL-lactic-coglycolic acid)-coated stainless steel. Biomaterials. 2012;33:8745-8756.
10. Pollak AN, Jones AL, Castillo RC, Bosse MJ, Mackenzie EJ. The Relationship between time to surgical debridement and incidence of infection after open high-energy lower extremity trauma. J Bone Joint Surg Am. 2010;92:7-15.

11. Towers AG, Stinson NE. The effect of an antimicrobial coating on metal implants: a pilot study in goats. Acta Orthopaedica. 1966;37:211-218.

12. Qu H, Knabe C, Burke M, Radin S, Garino J, Schaier T, Ducheyne P. Bactericidal micron-thin sol-gel films prevent pin tract and periprosthetic infection. Mil Med. 2014; 179(8S):29-33. 